\title{
3D laparoscopy does not reduce operative duration or errors in day-case laparoscopic cholecystectomy: a randomised controlled trial
}

\author{
Katie E. Schwab ${ }^{1,2,3} \cdot$ Nathan J. Curtis ${ }^{4,5} \cdot$ Martin B. Whyte ${ }^{6} \cdot$ Ralph V. Smith $^{1,7} \cdot$ Timothy A. Rockall $^{1,2}$. \\ Karen Ballard ${ }^{6} \cdot$ lain C. Jourdan ${ }^{2}$
}

Received: 28 March 2019 / Accepted: 1 July 2019 / Published online: 16 July 2019

(C) The Author(s) 2019

\begin{abstract}
Background Contemporary 3D platforms have overcome past deficiencies. Available trainee and laboratory studies suggest stereoscopic imaging improves performance but there is little clinical data or studies assessing specialists. We aimed to determine whether stereoscopic (3D) laparoscopic systems reduce operative time and number of intraoperative errors during specialist-performed laparoscopic cholecystectomy (LC).

Methods A parallel arm (1:1) randomised controlled trial comparing 2D and 3D passive-polarised laparoscopic systems in day-case LC using was performed. Eleven consultant surgeons that had each performed $>200$ LC (including > 10 3D LC) participated. Cases were video recorded and a four-point difficulty grade applied. The primary outcome was overall operative time. Subtask time and the number of intraoperative consequential errors as identified by two blinded assessors using a hierarchical task analysis and the observational clinical human reliability analysis technique formed secondary endpoints.

Results 112 patients were randomised. There was no difference in operative time between 2D and 3D LC (23:14 min $( \pm 10: 52)$ vs. $20: 17( \pm 9: 10)$, absolute difference $-14.6 \%, p=0.148)$ although $3 \mathrm{D}$ surgery was significantly quicker in difficulty grade 3 and 4 cases (30:23 $\min ( \pm 9: 24)$, vs. 18:02 $( \pm 7: 56), p<0.001)$. No differences in overall error count was seen (total 47 , median 1 , range $0-4$ vs. $45,1,0-3, p=0.62$ ) although there were significantly fewer $3 \mathrm{D}$ gallbladder perforations (15 vs. $6, p=0.034)$.

Conclusion 3D laparoscopy did not reduce overall operative time or error frequency in laparoscopic cholecystectomies performed by specialist surgeons. 3D reduced Calot's dissection time and operative time in complex cases as well as the incidence of iatrogenic gallbladder perforation (NCT01930344).
\end{abstract}

Keywords 3D $\cdot$ Three-dimensional $\cdot$ Laparoscopic $\cdot$ Cholecystectomy $\cdot$ Gallbladder $\cdot$ Trial

Previous communication Awarded the Gerhard Buess technology award for best presentation at the 24th European Association of Endoscopic Surgeons Congress, Amsterdam, The Netherlands, June 2016. The conference abstract has been previously published in a supplement of Surgical Endoscopy (Surg Endosc. 2017 Jun;31(Suppl 2):S262. https://doi.org/10.1007/s00464-017-5564-3 PMID: 28444491).

Electronic supplementary material The online version of this article (https://doi.org/10.1007/s00464-019-06961-1) contains supplementary material, which is available to authorized users.

Katie E. Schwab

katschwab@doctors.org.uk

Extended author information available on the last page of the article
The short-term patient benefits provided by laparoscopy present surgical challenges. The inherent loss of depth perception has been a source of focus for industry and led to the development and marketing of three-dimensional (3D) systems. Adoption of early 3D platforms was limited by poor image resolution and user side effects [1]. Technological advancements in processing and visual presentation have revived surgical interest as contemporary systems appear to have addressed these issues without increasing cognitive load [2-4].

Systematic reviews have concluded that 3D systems appear to improve task and operative time and reduce performance errors when compared to 2D laparoscopy [5, 6]. However, the role of 3D laparoscopy in routine clinical practice has not been sufficiently evaluated as the available 
literature predominantly focusses on trainee performance of box trainer tasks or comparative studies with significant methodological concerns reported [2, 5, 7]. Ex-vivo specialist performance has also been seen to improve but the paucity of clinical studies mean it is unclear if this translates to the delivery of laparoscopic interventions in the operating room $[8,9]$.

Therefore, we aimed to investigate whether the reported benefits in surgical efficiency and error reduction from the use of 3D laparoscopic systems were present in routine clinical practice. We hypothesised that 3D laparoscopy reduces the operative time and number of intraoperative errors enacted during laparoscopic cholecystectomy (LC) compared to the current $2 \mathrm{D}$ reference standard.

\section{Methods}

A single centre, parallel arm (1:1) randomised controlled trial (RCT) was designed in keeping with an IDEAL stage IIb exploration study as well as recommendations for 3D laparoscopic studies and the CONSORT principles (Supplementary Table 1) $[5,7,10]$. Research ethical approval was granted by the UK National Health Service East Midlands committee (ref: 13/EM/0092) and local research department (ref: 13SURN0004). This trial is registered (NCT01930344).

\section{Patient eligibility criteria}

Inclusion criteria were patients listed for elective day-case LC, age 18-80 and provision of written informed consent. All patients received an abdominal ultrasound scan and liver function tests. Additional pre-operative imaging was performed at the discretion of the responsible surgeon. Exclusion criteria were previous upper abdominal surgery, known common bile duct stones, cholecystectomy planned with any other combined surgical procedure (including bile duct exploration), planned overnight or post-operative inpatient stay and inability or refusal to provide written informed consent. In keeping with standard practice for day-case surgery, patients with an American Society of Anaesthesiologists physical classification score $>2$, age $>80$ or a body mass index $\geq 35 \mathrm{~kg} / \mathrm{m}^{2}$ were also excluded.

\section{Surgeon eligibility criteria and stereopsis testing}

All consultant surgeons performing laparoscopic cholecystectomy at the Royal Surrey County Hospital UK were approached to participate. All had performed a minimum of 200 independent day-case elective LC including at least 10 3D laparoscopic cases. Surgeons received a written information pack and face-to-face trial briefing. To enrol, surgeons had to provide written informed consent and undergo stereopsis testing (Wirt Fly sterotest (Stereo Optical Inc ${ }^{\circledR}$, Chicago, IL, USA). This evaluates both gross stereopsis (2500 to $1200 \mathrm{~s}$ of arc) and fine depth perception (800 to $40 \mathrm{~s}$ ). All participants were seen to have normal stereo acuity (defined as $\leq 120 \mathrm{~s}$ of arc).

\section{Equipment, set-up and procedures}

All cases were performed using either a Karl Storz IMAGE1 S D3-Link ${ }^{\mathrm{TM}}$ system with zero-degree $10 \mathrm{~mm}$ TIPCAM $^{\circledR} 1$ SPIES 3D video laparoscopes or Olympus 3DV-190 system with Endoeye ${ }^{\mathrm{TM}} 10 \mathrm{~mm}$ rigid 3D laparoscopes. Images were displayed on liquid crystal display high definition screens (Panasonic EJ-MDA32E-K, Panasonic ${ }^{\circledR}$ Europe, Wiesbaden, Germany or Sony LMD-2451MT, Sony Europe Ltd., Surrey, UK) and viewed with passive polarising glasses. 2D cases used identical equipment. Screen positioning and viewing distance was at the discretion of each surgical team. All surgeons used a four-port technique with dissection performed with Maryland forceps or hook diathermy. To maximise recruitment, generalisability of results and ethical and surgeon acceptability, no constraint on anaesthetic techniques, timing of surgery, precise operative technique, instrument use or intraoperative decision were made. On table cholangiography was performed at the discretion of the operating surgeon. All perioperative care proceeded as per local site policies.

\section{Randomisation procedure}

Upon provision of consent, each patient was allocated a unique trial ID as sole identifier. This was matched to a block plan of two options randomised over 120 stems which had been generated pre-trial. These results were placed in sealed envelopes, labelled by study ID, in the theatre admissions unit and opened during induction of anaesthesia maintaining allocation concealment. Given the sample size, further stratification was not undertaken.

\section{Observational clinical human reliability analysis (OCHRA)}

To assess whether 3D imaging influences intraoperative performance, analysis of intervention delivery was performed. The OCHRA technique assesses the interaction of humans with complex systems with the aim of highlighting the mode and mechanism behind error occurrence and increase awareness and data to aid future avoidance [11-14]. OCHRA involves structured analysis of operative case video to identify errors. In this study, consequential errors were defined "adverse events that required extra unplanned step(s) to correct or manage, or deviation from the standard operative task". OCHRA has been 
successfully applied to a variety of laparoscopic procedures including LC, cases performed within RCTs, as well as assessment of specialist surgical performance with reliability and face, construct and concurrent validity established [11-13, 15-18].

As surgical interventions can be considered as a series of interconnecting steps which can be further broken down into sub-tasks, a previously reported LC hierarchical task analysis (HTA) was utilised [14]. Each step was analysed for consequential errors and a model of error production applied to each event. Additionally, the nature, timepoint and brief description of each error event was captured and categorised using a pre-defined list of external error modes (EEM, Table 3) [14, 19]. OCHRA analysis was performed independently by two reviewers after completion of human factors and OCHRA training from expert assessors. Reviewers were blinded to trial arm, surgeon, date of surgery and all patient and clinical details.

\section{Endpoints and sample size}

The primary end-point was total surgical time (from grasping and elevation of the gallbladder fundus until complete detachment of the gallbladder from the liver bed) (Table 2). As there was no prior 3D LC research to guide sample size calculations, mean operative times from a meta-analysis of 12 four-port LC RCTs (all in 2D) were reviewed showing a weighted mean time of $45.8 \mathrm{~min}$ [20]. A minimally clinically important difference of $12 \mathrm{~min}$ (25\%) was adopted. Using a two-sided test ( $\alpha 0.05, \beta 0.8)$, a minimum of 50 patients per arm would be required. Allowing for attrition, a recruitment target of 120 was selected. Pre-defined secondary endpoints were time for each operative task zone (Table 2) and number of consequential errors enacted.

\section{Data collection}

The integrated stack systems (AIDA ${ }^{\mathrm{TM}}$ ), Karl Storz Endoskopy, Germany and image management hub IMH-20, Olympus Europe, Hamburg, Germany) were used to record unedited, deidentified procedures. Irrespective of trial arm, all videos were recorded in 2D without sound or extra corporeal views. To reduce heterogeneity and ensure comparable assessment, video files were edited using iMovie for MacOS (v10, Apple Inc ${ }^{\mathrm{TM}}$, Cupertino, CA, USA) to show the three task sections forming the primary endpoint which were left unaltered (Table 2). If an on table cholangiogram was performed, this segment was removed from the video and not analysed nor contributed to any endpoint. Edited videos were collated and issued for assessment at least 3 months after surgery.

\section{Case difficulty grading}

Procedural difficulty varies and can influence surgical time and error rate [21]. Therefore, an intraoperative assessment of macroscopic gallbladder pathology was made using a validated scale: grade 1 (thin-walled gallbladder, no adhesions), grade 2 (filmy gallbladder adhesions), grade 3 (thick-walled or surrounded by adhesions) or grade 4 (dense adhesions, attachment of adjacent organs or gallbladder mucocele or empyema) [22].

\section{Statistical analyses}

The data were analysed using SPSS (v25.0; SPSS Inc, Chicago, IL, USA). Data were tested for normality with the Shapiro-Wilk test and detrended Q-Q plots and compared with parametric or non-parametric tests as appropriate. Unpaired $T$ Test, Mann-Whitney $U$ and Kruskal-Wallis testing were used to compare means/medians from normal and non-normally distributed populations respectively. For categorical data, association between groups was analysed with cross-tabulation, Fisher's exact test or Pearson's Chi squared. Operative time was log transformed and $2 \mathrm{D}$ and $3 \mathrm{D}$ cases compared with ANCOVA using gallbladder case grade as a covariant. The degree of inter-rater agreement between OCHRA observers was compared using Cohen's kappa $(\kappa)$ with the $95 \%$ confidence interval (CI) calculated using the standard error of $\kappa$. Data are displayed as means with standard deviations unless otherwise specified. Comparative results are reported as (2D vs. 3D) throughout. Intention to treat data is presented although where a complete case recording was necessary for analysis, a per protocol approach was used. Statistical significance was defined as $p<0.05$.

\section{Results}

136 patients underwent day-case LC between May 2013 and September 2014. Trial CONSORT diagram is shown in Fig. 1. Of the 120 patients screened, 113 were eligible and $112(99 \%)$ recruited. The attrition rate was $11.6 \%$ and equal between arms (incomplete or corrupt case video $(n=7)$, conversion to open surgery $(n=2,1.8 \%, 1$ per arm), LC performed by a trainee ( $n=2$, one per arm), subtotal cholecystectomy $(n=1)$ and one patient declined surgery). In total, 99 patients underwent day-case LC with a complete video available.

$74 \%$ of participants were female. Mean age was 52 years (range 24-80). Baseline patient characteristics were evenly distributed between the trial arms (Table 1). Biliary colic 


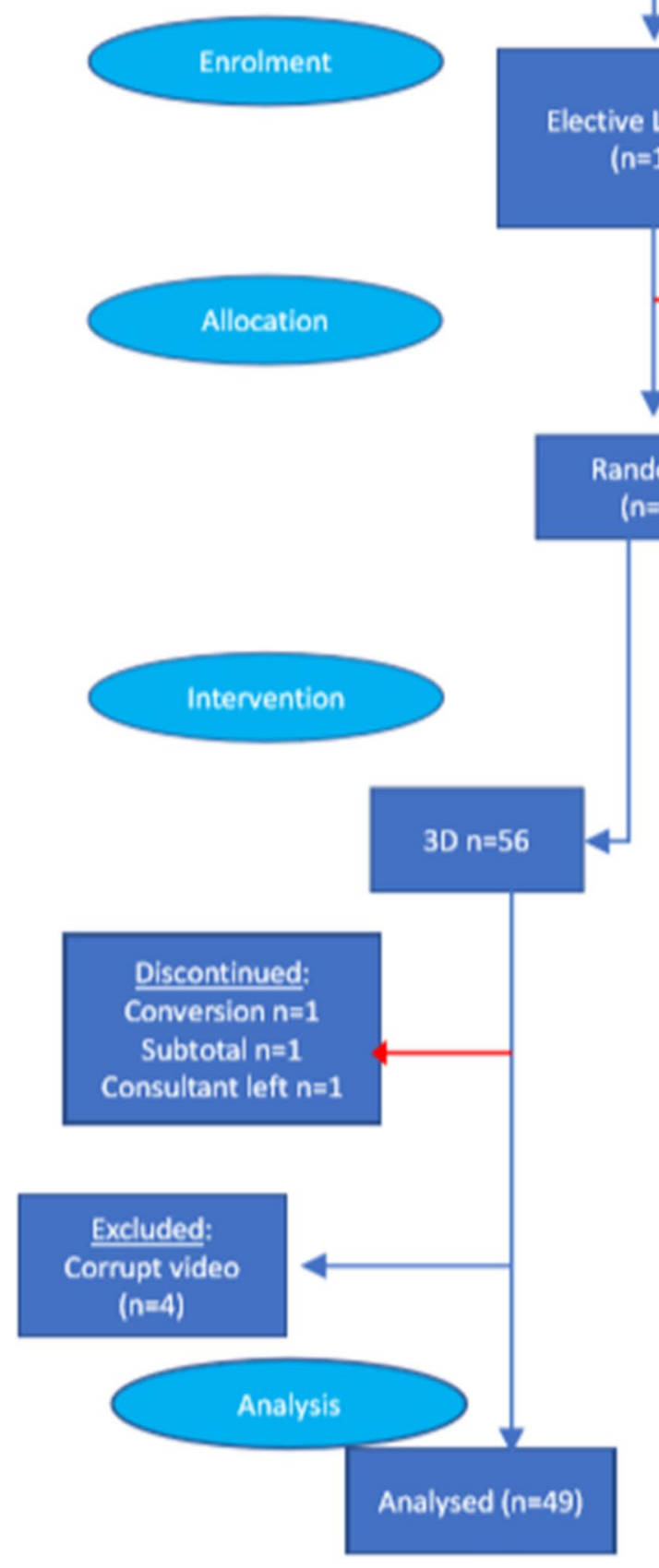

Fig. 1 Trial CONSORT diagram. 136 day-case LC were performed during the study period. $16(11.7 \%)$ were not approached due to researcher unavailability. Of the 120 patients screened for eligibility,

was the most common indication for surgery (52\%) followed by past cholecystitis (39\%), gallstone pancreatitis
Total eligible

patients

$n=136$

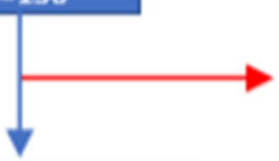

chole

$(n=120)$

Potential Lap Choles

not approached

$\mathrm{N}=16$

\section{Excluded ( $n=8$ )}

Not meeting inclusion

criteria $(\mathrm{n}=7)$

Declined participation

$(n=1)$

\section{andomised}

( $n=112$ )
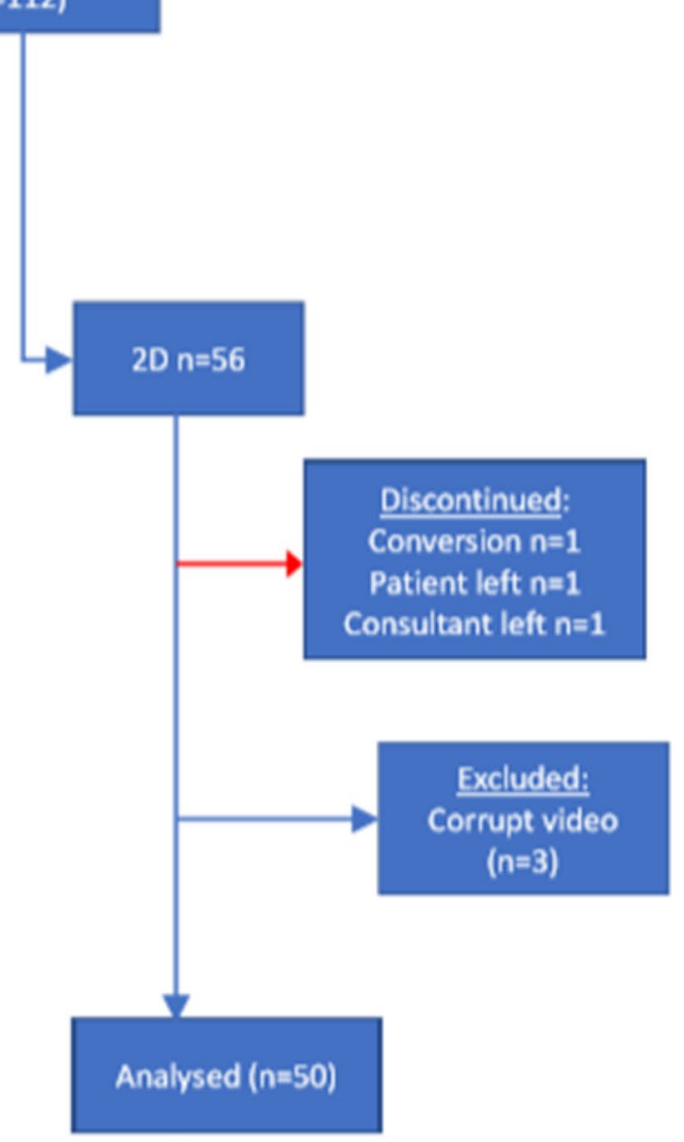

113 approached with 112 consenting to trial entry $(99.1 \%, 82.4 \%$ of all unit LC). Attrition was $11 \%$, equal between the arms and inside study design. Incomplete video was the main reason

(5\%), gallbladder polyp (2\%) and passed common bile duct stone $(1 \%)$. 
Table 1 Patient demographics, indication and LC case difficulties

\begin{tabular}{|c|c|c|c|c|c|c|c|}
\hline & \multicolumn{3}{|l|}{$2 \mathrm{D}$} & \multicolumn{3}{|l|}{$3 \mathrm{D}$} & \multirow[t]{2}{*}{$p$} \\
\hline & Mean (SD) & Count & Column $N(\%)$ & Mean (SD) & Count & Column $N(\%)$ & \\
\hline Age & $53(14)$ & & & $51(16)$ & & & 0.679 \\
\hline \multicolumn{8}{|l|}{ Gallbladder case difficulty grade } \\
\hline 1 & & 17 & 34 & & 23 & 46.9 & \multirow[t]{4}{*}{0.991} \\
\hline 2 & & 22 & 44 & & 7 & 14.3 & \\
\hline 3 & & 7 & 14 & & 14 & 28.6 & \\
\hline 4 & & 4 & 8 & & 5 & 10.2 & \\
\hline \multicolumn{8}{|l|}{ Sex } \\
\hline Females & & 34 & 68 & & 40 & 81.6 & \multirow[t]{2}{*}{0.119} \\
\hline Males & & 16 & 32 & & 9 & 18.4 & \\
\hline \multicolumn{8}{|l|}{ Indication for surgery } \\
\hline Biliary colic & & 26 & 52 & & 26 & 54.2 & \multirow[t]{5}{*}{0.397} \\
\hline Cholecystitis & & 18 & 36 & & 20 & 41.7 & \\
\hline Gallstone pancreatitis & & 2 & 4 & & 2 & 4.2 & \\
\hline Gallbladder polyp & & 3 & 6 & & 0 & & \\
\hline Passed common bile duct stone & & 1 & 2 & & 0 & & \\
\hline
\end{tabular}

As might be expected from the inclusion criteria there were significantly more lower grade cases $(p<0.001)$

\section{Operative case complexity}

In keeping with study inclusion criteria overall there were significantly higher numbers of low-grade cases (grade 1 $n=40$, grade $2 n=29$, grade $3 n=21$ and grade $4 n=9$; $p<0.001$, Table 1). Overall gallbladder grades were equal between the trial arms $(p=0.991)$ although the 3D arm contained a significantly higher proportion of grade 3 and 4 cases $(p=0.011)$. No surgeon reported any eye symptoms or complaints during the duration of this study.

\section{Operative time}

The mean time to complete a 3D LC was 20:17 ( $\pm 9: 10)$ minutes compared to $23: 14$ ( $\pm 10: 52)$, absolute difference $-14.6 \%, p=0.148$. Operative time increased with each gallbladder grade (grade $1=14: 24 \min ( \pm 4: 42)$ vs. grade $2=23: 01( \pm 8: 50)$ vs. grade $3=27: 07( \pm 7: 28)$ vs. grade $4=38: 02$ ( \pm 9.22$), p<0.001$, Fig. 2). Grade 3 and 4 cases were performed significantly faster in 3D (18:02 $( \pm 9: 24)$ vs. 30:23, $p<0.001$ ).

Following natural log transformation of the three hierarchical task zones, a normal distribution was seen (Shapiro-Wilk test $p=0.23$ ). ANCOVA analysis showed that higher gallbladder grades were significantly associated with longer operative times (partial $\eta^{2}=0.507, p<0.001$, Table 2). Overall operative times were reduced with $3 \mathrm{D}$ systems, but this did not reach statistical significance with a small effect size observed (partial $\eta^{2}=0.039, p=0.056$ ). HTA defined operative task 1-3 breakdown showed a statistically significant time reduction for task one when 3D was

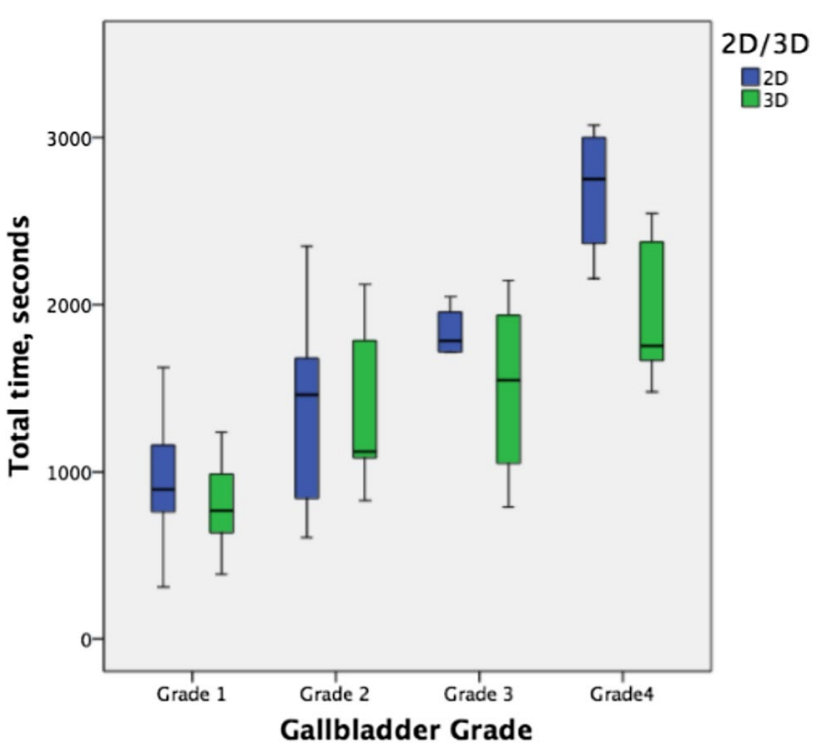

Fig. 2 Gallbladder grade is seen to have a larger impact on operative time. 3D was significantly faster for grade 3 and 4 cases

used (median $724 \mathrm{~s}$ (interquartile range 380-1068) vs. 540 $(288-792, p=0.013)$ ) but not task 2 or 3 (Table 2).

\section{OCHRA error analysis}

99 complete videos were available for analysis comprising 2156 min of LC surgery. A total of 92 intraoperative errors were identified (median 1 per case, range $0-4$ ). No differences were seen between the 2D and 3D arms (median 1, 
Table 2 Hierarchical task analysis used in the trial. Adapted from the reports by Joice et al. [14] and Tang et al. [11]

\begin{tabular}{|c|c|c|c|c|c|c|c|}
\hline Task & Start point & End point & Trial arm & Median (IQR) (s) & $p$ & $\begin{array}{l}\text { Dependent variable } \\
\text { of natural log of time. } \\
\text { Partial } \eta^{2}\end{array}$ & $p$ \\
\hline \multirow{2}{*}{$\begin{array}{l}\text { 1. Dissection of } \\
\text { Calot's triangle }\end{array}$} & \multirow{2}{*}{$\begin{array}{l}\text { Grasping of fundus } \\
\text { and elevating }\end{array}$} & \multirow{2}{*}{$\begin{array}{l}\text { Clear identification } \\
\text { of cystic artery and } \\
\text { duct }\end{array}$} & $2 \mathrm{D}$ & $724(380-1068)$ & \multirow{2}{*}{0.061} & \multirow{2}{*}{0.063} & \multirow{2}{*}{0.013} \\
\hline & & & $3 \mathrm{D}$ & $540(288-792)$ & & & \\
\hline \multirow{2}{*}{$\begin{array}{l}\text { 2. Clipping and divid- } \\
\text { ing cystic artery and } \\
\text { cystic duct }\end{array}$} & \multirow{2}{*}{$\begin{array}{l}\text { Appearance of clip } \\
\text { applicator }\end{array}$} & \multirow{2}{*}{$\begin{array}{l}\text { Cystic artery and duct } \\
\text { divided }\end{array}$} & $2 \mathrm{D}$ & $140.5(44-237)$ & \multirow[t]{2}{*}{0.23} & \multirow[t]{2}{*}{0.007} & \multirow[t]{2}{*}{0.414} \\
\hline & & & $3 \mathrm{D}$ & $182(76-288)$ & & & \\
\hline \multirow{2}{*}{$\begin{array}{l}\text { 3. Detaching gallblad- } \\
\text { der from liver bed }\end{array}$} & \multirow{2}{*}{$\begin{array}{l}\text { At completion of } \\
\text { cystic artery and } \\
\text { duct division }\end{array}$} & \multirow{2}{*}{$\begin{array}{l}\text { Gallbladder fully } \\
\text { removed from liver } \\
\text { bed }\end{array}$} & $2 \mathrm{D}$ & $324.5(203.5-445.5)$ & \multirow[t]{2}{*}{0.894} & \multirow[t]{2}{*}{0.000} & \multirow[t]{2}{*}{0.941} \\
\hline & & & $3 \mathrm{D}$ & $281(196-366)$ & & & \\
\hline \multirow[t]{2}{*}{ Total operative time } & \multirow{2}{*}{$\begin{array}{l}\text { Grasping of fundus } \\
\text { and elevating }\end{array}$} & \multirow{2}{*}{$\begin{array}{l}\text { Gallbladder fully } \\
\text { removed from liver } \\
\text { bed }\end{array}$} & $2 \mathrm{D}$ & 1287 (834-1783) & \multirow[t]{2}{*}{0.148} & \multirow[t]{2}{*}{0.039} & \multirow[t]{2}{*}{0.056} \\
\hline & & & $3 \mathrm{D}$ & 1070 (790-1616) & & & \\
\hline
\end{tabular}

Time (s) is displayed. No differences are seen in the direct comparison but after natural transformation a significant difference in Calot's dissection alone is seen

Table 3 External error modes-this model considers errors as being either 'inter-step' (the correct steps being performed in the correct order; error modes 1-6), or 'intra-step' (the execution, or lack of, the subtask; error modes 7-10). Adapted from Cuschieri et al. [32]

\begin{tabular}{|c|c|c|c|c|c|c|c|}
\hline \multirow[t]{2}{*}{ External error mode } & \multirow[t]{2}{*}{$2 \mathrm{D}$ error count } & \multirow[t]{2}{*}{$3 \mathrm{D}$ error count } & \multirow[t]{2}{*}{ Error event enacted } & \multicolumn{2}{|c|}{$\begin{array}{l}\text { Inter- } \\
\text { step } \\
\text { errors } \\
\text { (EEM } \\
1-6)\end{array}$} & \multicolumn{2}{|c|}{$\begin{array}{l}\text { Intra- } \\
\text { step } \\
\text { errors } \\
\text { (EEM } \\
7-10)\end{array}$} \\
\hline & & & & $2 \mathrm{D}$ & $3 \mathrm{D}$ & $2 \mathrm{D}$ & $3 \mathrm{D}$ \\
\hline Step is not done & 1 & 1 & Calot's triangle bleeding & 1 & 1 & & \\
\hline Step is partially completed & 5 & 7 & Bleeding from gallbladder & 0 & 0 & & \\
\hline Step is repeated & 2 & 4 & Injury to liver & 0 & 0 & & \\
\hline Second step is done in addition & 1 & 2 & Clip application error & 8 & 13 & & \\
\hline Second step is done instead of first step & 0 & 0 & Gall bladder perforation & 0 & 0 & & \\
\hline Step is done out of sequence & 0 & 0 & & & & & \\
\hline $\begin{array}{l}\text { Step is done with too much force/speed/depth/distance/time/ } \\
\text { rotation }\end{array}$ & 20 & 17 & Calot's triangle bleeding & & & 8 & 6 \\
\hline $\begin{array}{l}\text { Step is done with too little force/speed/depth/distance/time/ } \\
\text { rotation }\end{array}$ & 3 & 3 & Bleeding from gallbladder & & & 8 & 12 \\
\hline Step is done in wrong orientation/direction/point in space & 15 & 11 & Injury to liver & & & 5 & 5 \\
\hline \multirow[t]{2}{*}{ Step is done on/with the wrong object } & 0 & 0 & Clip application error & & & 2 & 2 \\
\hline & & & Gall bladder perforation & & & 15 & 6 \\
\hline Sum & 47 & 45 & & 9 & 14 & 38 & 31 \\
\hline
\end{tabular}

OCHRA results are shown. No difference in error modes are seen between the 2D and 3D cases. Intra-step (executional, EEM 7-10) errors accounted for $75 \%$ of error events. The only significant difference observed was fewer gallbladder perforations with 3D surgery $(p=0.034)$

range $0-4$, total 47 , cases with error(s) $66 \%$, vs. 1, 0-3, 45, $61 \%, p=0.62)$. Excellent inter-rater reliability was seen $(\kappa=0.81(95 \%$ CI $0.7-0.92), p<0.001$, Supplementary Table 1).

Errors were more frequent in higher grade gallbladder cases (grade $1=0.75$ per case, grade $2=0.97$, grade $3=0.86$ and grade $4=1.78 ; p<0.001$ ) but when controlling for grade, no differences were seen between $2 \mathrm{D}$ and
3D LC $(p=0.879)$. There was no difference in error counts between the three surgical task phases (39 vs. 25 vs. 27 , $p=0.181)$. OCHRA categorical data is displayed in Table 3 . Executional errors (EEM 7-10) accounted for $75 \%$ of error events with no difference between the trial arms $(p=0.186)$. With regards to consequential errors, gallbladder perforations were significantly reduced in the $3 \mathrm{D}$ cases ( 15 vs. 6 , $p=0.034$ ) otherwise no differences were seen in the external 
error modes or specific nature and frequency of errors between the trial arms (Table 3).

\section{Discussion}

The minimal access surgery revolution is dependent on advancements of technology and technique. Stereoptic laparoscopy overcomes the inherent loss of depth perception associated with 2D systems. Laboratory-based studies with trainee and specialist participants have suggested 3D allows faster performance with fewer errors, but their findings cannot be assumed to be applicable to actual operating theatre performance [3]. As there is increasing uptake of 3D systems without supportive evidence it could be argued that the innovation has outpaced surgical evaluation.

We performed an RCT assessing the impact on time and errors using LC as a representative high-volume index procedure and additionally as the Cochrane 2D/3D LC review was based on a single 1998 RCT [23, 24]. We incorporated all methodological recommendations for 3D studies advocated by the available 3D systematic reviews and evaluation of surgery as defined by the IDEAL collaborative $[5,7,10]$.

We saw a non-clinically nor statistically significant 3-min reduction in operative time with 3D arm primarily from faster Calot's triangle dissection. Case difficulty could represent a major confounding variable within LC studies. We applied a four-point difficulty classification based on direct intraoperative visualisation recently validation in our population and saw a significant increase in operation time with each additional grade [22]. Although there were only 21 grade 3 and 9 grade 4 cases in the trial and there was a higher proportion of these within the 3D arm, 3D was significantly faster in these potentially challenging cases with a $40 \%$ operative time reduction.

Operative duration alone is an insufficient measure of surgical performance. Direct observation of the intraoperative period was performed independently by two blinded reviewers using the structured, validated OCHRA technique as this is where any impact of imaging technology is most likely to be evident. Provision of stereoscopic imaging did not alter the number of enacted error events or the underlying external error mode. Significantly fewer perforations of the gallbladder, which can present significant consequences to patients [25], occurred in 3D cases as the only difference between the arms.

Our findings, which could be expected to be widely applicable, are comparable with the original 1998 and very recent $2 \mathrm{D} / 3 \mathrm{D}$ LC RCT reports although our notable absence of subjectively reported side effects and eye symptoms suggests contemporary 3D technology holds improved usability $[24,26]$. Our data suggests specialist LC performance was not altered by the technology used, possibly as the participating surgeon experience allowed them to overcome the loss of depth perception. There is supportive evidence for 3D laparoscopy for trainees, but the specialist surgeon proficiency gain curve has not been defined [3].

Surgical technologies undergo intensive development and safety testing but efficacy assessment including within-operating room settings are not mandatory for licencing which contrasts with regulatory requirements in other healthcare areas. Surgical intervention studies can present challenges not encountered in other areas of clinical research [10]. Our study is strengthened by the randomised design that aimed to reduce potential bias that can influence comparative studies of surgical technology. Robotics represents another area of contemporary debate where high level evidence has contradicted previous favourable reports with concerns raised regarding the influence of industry funding on study reporting $[27,28]$. A number of questions on 3D laparoscopy remain, particularly regarding health economic data. Although not formally studied here, our results suggest no meaningful difference in resources would be expected.

We successfully recruited to time and target and observed very high recruitment of eligible patients, however, our findings should be considered in light of some limitations. As there were no contemporary 3D LC data available at the time of study design we based our power calculation on external 2D LC RCT reports with differing operative time definitions [20]. Our operative duration was considerably faster in both 2D and 3D LC which likely invalidates this calculation and risks introduction of type II errors although the small observed time difference is unlikely to be clinically significant or relevant to healthcare providers. Ideally, trial equipment would have been standardised but regular simultaneous day-case LC theatre lists necessitated use of a second 3D comparable passive polarising technology platform although this was from a second manufacturer. Reassuringly no outcome differences were seen between the two systems.

We observed that case difficulty was a major cofounding variable with a larger impact on operative time than the imaging system used. The case complexity distributions were unequal between the trial arms with more complex cases in the 3D arm which affected the primary endpoint comparison. As there is no reliable method to pre-operatively predict case difficulty, we would advise future researchers to consider on table randomisation which allows stratification for the observed difficulty. This has been successfully used in surgical interventional RCTs to ensure participant and procedure eligibility [29]. Although we complied with the CONSORT criteria and $80 \%$ of elective UK LC are now performed as day-case procedures [30], selection bias cannot be fully excluded as more comorbid patients, potentially difficult LC cases (including the acute cases and the emergent setting) were excluded. Finally, case video review does not 
capture human factors that may influence surgical performance and procedure duration [31].

\section{Conclusion}

3D laparoscopy did not reduce overall operative time or error frequency in laparoscopic cholecystectomies performed by specialist surgeons. 3D reduced Calot's dissection time and operative time in complex cases as well as the incidence of iatrogenic gallbladder perforation (NCT01930344).

Acknowledgements The authors gratefully acknowledge the support and contribution of the following in the delivery of this study: All participating surgeons, Alison Snook and Matt Dunstan (Minimal Access Therapy Training Unit, University of Surrey), all theatre teams at the day-case surgery unit and the research and development office, Royal Surrey County Hospital, Guildford, UK. OCHRA training and human factors training was provided by Terema Ltd., ICENI Centre, Colchester and Mr. Danilo Miskovic and Ms Susannah Wyles (Department of Surgery of Cancer, Imperial College London).

Funding 3D laparoscopic systems were provided by Karl Storz Endoscopy (UK) Ltd and Olympus UK \& Ireland Ltd as a free research loan. Karl Storz and Olympus had no input to the design, set-up, running, data acquisition, analysis, interpretation nor preparation of this manuscript.

\section{Compliance with ethical standards}

Disclosures Ms. Schwab, Mr. Curtis, Dr. Whyte, Mr. Smith, Prof. Rockall, Prof. Ballard and Mr. Jourdan confirm they hold no conflict of interest or financial ties to disclose.

Open Access This article is distributed under the terms of the Creative Commons Attribution 4.0 International License (http://creativecommons.org/licenses/by/4.0/), which permits unrestricted use, distribution, and reproduction in any medium, provided you give appropriate credit to the original author(s) and the source, provide a link to the Creative Commons license, and indicate if changes were made.

\section{References}

1. Schwab K, Smith R, Brown V, Whyte M, Jourdan I (2017) Evolution of stereoscopic imaging in surgery and recent advances. World J Gastrointest Endosc 9(8):368-377

2. Vettoretto N, Foglia E, Ferrario L, Arezzo A, Cirocchi R, Cocorullo $\mathrm{G}$ et al (2018) Why laparoscopists may opt for three-dimensional view: a summary of the full HTA report on $3 \mathrm{D}$ versus $2 \mathrm{D}$ laparoscopy by S.I.C.E. (Societa Italiana di Chirurgia Endoscopica e Nuove Tecnologie). Surg Endosc 32(6):2986-2993

3. Arezzo A, Vettoretto N, Francis NK, Bonino MA, Curtis NJ, Amparore D et al (2018) The use of 3D laparoscopic imaging systems in surgery: EAES consensus development conference 2018. Surg Endosc. https://doi.org/10.1007/s00464-018-06612-X

4. Curtis NJ, Conti JA, Dalton R, Rockall TA, Allison AS, Ockrim JB et al (2019) 2D versus 3D laparoscopic total mesorectal excision: a developmental multicentre randomised controlled trial. Surg Endosc. https://doi.org/10.1007/s00464-018-06630-9

5. Sorensen SM, Savran MM, Konge L, Bjerrum F (2016) Threedimensional versus two-dimensional vision in laparoscopy: a systematic review. Surg Endosc 30(1):11-23

6. Cheng J, Gao J, Shuai X, Wang G, Tao K (2016) Two-dimensional versus three-dimensional laparoscopy in surgical efficacy: a systematic review and meta-analysis. Oncotarget 7(43):70979-70990

7. Sakata S, Watson MO, Grove PM, Stevenson AR (2016) The conflicting evidence of three-dimensional displays in laparoscopy: a review of systems old and new. Ann Surg 263(2):234-239

8. Smith R, Schwab K, Day A, Rockall T, Ballard K, Bailey M et al (2014) Effect of passive polarizing three-dimensional displays on surgical performance for experienced laparoscopic surgeons. $\mathrm{Br} \mathbf{J}$ Surg 101(11):1453-1459

9. Wilhelm D, Reiser S, Kohn N, Witte M, Leiner U, Muhlbach L et al (2014) Comparative evaluation of HD 2D/3D laparoscopic monitors and benchmarking to a theoretically ideal 3D pseudodisplay: even well-experienced laparoscopists perform better with 3D. Surg Endosc 28(8):2387-2397

10. McCulloch P, Altman DG, Campbell WB, Flum DR, Glasziou P, Marshall JC et al (2009) No surgical innovation without evaluation: the IDEAL recommendations. Lancet 374(9695):1105-1112

11. Tang B, Hanna GB, Joice P, Cuschieri A (2004) Identification and categorization of technical errors by observational clinical human reliability assessment (OCHRA) during laparoscopic cholecystectomy. Arch Surg 139(11):1215-1220

12. Foster JD, Miskovic D, Allison AS, Conti JA, Ockrim J, Cooper EJ et al (2016) Application of objective clinical human reliability analysis (OCHRA) in assessment of technical performance in laparoscopic rectal cancer surgery. Tech Coloproctol 20(6):361-367

13. Miskovic D, Ni M, Wyles SM, Parvaiz A, Hanna GB (2012) Observational clinical human reliability analysis (OCHRA) for competency assessment in laparoscopic colorectal surgery at the specialist level. Surg Endosc 26(3):796-803

14. Joice P, Hanna GB, Cuschieri A (1998) Errors enacted during endoscopic surgery-a human reliability analysis. Appl Ergon 29(6):409-414

15. Tang B, Hanna GB, Bax NM, Cuschieri A (2004) Analysis of technical surgical errors during initial experience of laparoscopic pyloromyotomy by a group of Dutch pediatric surgeons. Surg Endosc 18(12):1716-1720

16. van Rutte P, Nienhuijs SW, Jakimowicz JJ, van Montfort G (2017) Identification of technical errors and hazard zones in sleeve gastrectomy using OCHRA: "OCHRA for sleeve gastrectomy". Surg Endosc 31(2):561-566

17. Talebpour M, Alijani A, Hanna GB, Moosa Z, Tang B, Cuschieri A (2009) Proficiency-gain curve for an advanced laparoscopic procedure defined by observation clinical human reliability assessment (OCHRA). Surg Endosc 23(4):869-875

18. Mishra A, Catchpole K, Dale T, McCulloch P (2008) The influence of non-technical performance on technical outcome in laparoscopic cholecystectomy. Surg Endosc 22(1):68-73

19. Cuschieri A (2006) Nature of human error: implications for surgical practice. Ann Surg 244(5):642-648

20. Pisanu A, Reccia I, Porceddu G, Uccheddu A (2012) Meta-analysis of prospective randomized studies comparing single-incision laparoscopic cholecystectomy (SILC) and conventional multiport laparoscopic cholecystectomy (CMLC). J Gastrointest Surg 16(9):1790-1801

21. Eijkemans MJ, van Houdenhoven M, Nguyen T, Boersma E, Steyerberg EW, Kazemier G (2010) Predicting the unpredictable: a new prediction model for operating room times using individual characteristics and the surgeon's estimate. Anesthesiology 112(1):41-49 
22. Griffiths EA, Hodson J, Vohra RS, Marriott P, Katbeh T, Zino S et al (2019) Utilisation of an operative difficulty grading scale for laparoscopic cholecystectomy. Surg Endosc 33(1):110-121

23. Gurusamy KS, Sahay S, Davidson BR (2011) Three dimensional versus two dimensional imaging for laparoscopic cholecystectomy. Cochrane Database Syst Rev 2011(1):CD006882

24. Hanna GB, Shimi SM, Cuschieri A (1998) Randomised study of influence of two-dimensional versus three-dimensional imaging on performance of laparoscopic cholecystectomy. Lancet 351(9098):248-251

25. Brockmann JG, Kocher T, Senninger NJ, Schurmann GM (2002) Complications due to gallstones lost during laparoscopic cholecystectomy. Surg Endosc 16(8):1226-1232

26. Koppatz H, Harju J, Siren J, Mentula P, Scheinin T, Sallinen V (2019) Three-dimensional versus two-dimensional high-definition laparoscopy in cholecystectomy: a prospective randomized controlled study. Surg Endosc. https://doi.org/10.1007/s00464-01906666-5

27. Jayne D, Pigazzi A, Marshall H, Croft J, Corrigan N, Copeland J et al (2017) Effect of robotic-assisted vs conventional laparoscopic surgery on risk of conversion to open laparotomy among patients undergoing resection for rectal cancer: the ROLARR randomized clinical trial. JAMA 318(16):1569-1580

28. Criss CN, MacEachern MP, Matusko N, Dimick JB, MaggardGibbons M, Gadepalli SK (2019) The impact of corporate payments on robotic surgery research: a systematic review. Ann Surg 269(3):389-396

29. Cornish J, Harries RL, Bosanquet D, Rees B, Ansell J, Frewer N et al (2016) Hughes Abdominal Repair Trial (HART) — abdominal wall closure techniques to reduce the incidence of incisional hernias: study protocol for a randomised controlled trial. Trials 17(1):454

30. CholeS Study Group WMRC (2016) Population-based cohort study of outcomes following cholecystectomy for benign gallbladder diseases. Br J Surg 103(12):1704-1715

31. Gjeraa K, Spanager L, Konge L, Petersen RH, Ostergaard D (2016) Non-technical skills in minimally invasive surgery teams: a systematic review. Surg Endosc 30(12):5185-5199

32. Cuschieri GB, Hanna NK, Francis A (2001) Psychomotor ability testing and human reliability analysis (HRA) in surgical practice. Minim Invasive Therapy Allied Technol 10(3):181-195

Publisher's Note Springer Nature remains neutral with regard to jurisdictional claims in published maps and institutional affiliations.

\section{Affiliations}

\section{Katie E. Schwab ${ }^{1,2,3} \cdot$ Nathan J. Curtis ${ }^{4,5} \cdot$ Martin B. Whyte ${ }^{6} \cdot$ Ralph V. Smith $^{1,7} \cdot$ Timothy A. Rockall $^{1,2}$. Karen Ballard ${ }^{6} \cdot$ lain C. Jourdan ${ }^{2}$}

1 Minimal Access Therapy Training Unit, University of Surrey, Daphne Jackson Road, Guildford, UK

2 Department of General Surgery, Royal Surrey County Hospital, Egerton Road, Guildford, UK

3 Department of Surgery, Royal Bournemouth and Christchurch Hospitals NHS Foundation Trust, Castle Lane East, Bournemouth, UK

4 Department of Surgery and Cancer, Imperial College London, Praed Street, London, UK
5 Department of General Surgery, Yeovil District Hospital NHS Foundation Trust, Higher Kingston, Yeovil, UK

6 University of Surrey, Guildford, UK

7 Department of Surgery, Frimley Park Hospital, Portsmouth Rd, Frimley, UK 